\title{
Desain Rubrik Kemampuan Berkolaborasi Siswa SMP dalam Materi Pemantulan Cahaya
}

\author{
Hermawan $^{\text {a) }}$, Parsaoran Siahaan ${ }^{\text {b) }}$, Endi Suhendi ${ }^{\text {c) }}$, Ida Kaniawati ${ }^{\text {d) }}$, \\ Achmad Samsudin ${ }^{\text {e) }}$, Anggi Hanif Setyadin ${ }^{\text {f) }}$, Syarif Rokhmat Hidayat ${ }^{\text {g) }}$ \\ Departemen Pendidikan Fisika, FPMIPA, Universitas Pendidikan Indonesia, \\ Jalan Dr. Setiabudhi No. 229, Bandung 40154 \\ Email: a)hermawan13@student.upi.edu, ${ }^{b}$ parsaoransiahaan@upi.edu, ${ }^{c}$ endis@upi.edu,

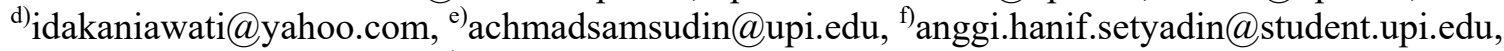 \\ g) syarif.rokhmat.hidayat@student.upi.edu
}

\begin{abstract}
This study aims to develop a rubric of students' collaboration skills in junior high school on light reflection materials. The collaboration skills are one of the important competencies of the 21st century so that teachers in the field must have their rubric to measure students' collaboration skills. The rubric is based on the adaptation and modification of the collaboration skills section of the International Reading Association (IRA) (2005). The research method used is the method of research and development of 4D (define, design, develop and disseminate) 2D (restricted and design) design model. Aspects that are adapted and modified are contributions, time management, problem solving, working with others and research techniques that are trained on the activity of light reflecting material. Each aspect is given a score of 1 - 4 with 1 (less), 2 (sufficient), 3 (good) and 4 (excellent). Through the define and design stage, a collaboration scoring rubric for junior high school students has been developed in light reflection materials based on adaptation and modification of the collaboration skills framework of the International Reading Association (IRA) (2005).
\end{abstract}

Keywords: collaboration skills, collaboration rubric skills, group investigation.

\begin{abstract}
Abstrak
Penelitian ini bertujuan untuk mengembangkan rubrik penilaian kemampuan berkolaborasi siswa SMP terkait materi pemantulan cahaya. Kemampuan berkolaborasi adalah salah satu kompetensi penting abad ke-21 sehingga guru di lapangan harus memiliki rubrik tersendiri untuk mengukur kemampuan berkolaborasi siswa. Rubrik disusun berdasarkan adaptasi dan modifikasi rubrik kemampuan berkolaborasi dari International Reading Association (IRA) (2005). Metode penelitian yang digunakan adalah metode penelitian dan pengembangan model intruksional 4D (define, design, develop and disseminate) yang dibatasi hanya 2D (define and design). Aspek yang diadaptasi dan dimodifikasi yaitu kontribusi, manajemen waktu, pemecahan masalah, bekerja dengan orang lain dan teknik penyelidikan yang dilatihkan pada kegiatan percobaan pemantulan cahaya. Setiap aspek diberi skor 1 - 4 dengan keterangan 1 (kurang), 2 (cukup), 3 (baik) dan 4 (sangat baik). Melalui tahap define dan design yang dilakukan, telah dikembangkan rubrik penilaian kemampuan berkolaborasi untuk siswa SMP dalam materi pemantulan cahaya berdasarkan adaptasi dan modifikasi rubrik kemampuan berkolaborasi dari International Reading Association (IRA) (2005).
\end{abstract}

Kata-kata Kunci: kemampuan berkolaborasi, rubrik kemampuan berkolaborasi, grup investigasi. 


\section{PENDAHULUAN}

Saat ini salah satu faktor penting yang dapat mendukung kemajuan bangsa Indonesia yaitu pendidikan. Indikator kemajuan suatu negara salah satunya adalah perhatian yang lebih dari setiap warga negara terhadap perkembangan zaman saat ini yaitu abad 21 yang ditandai dengan perkembangan sains dan teknologi yang sangat pesat. Setiap siswa wajib mendapatkan pendidikan yang tepat sehingga dapat memenuhi kemampuan abad 21. Ada empat kemampuan yang harus dimiliki siswa pada abad ke-21 yaitu: 1) Berkomunikasi dengan jelas; 2) Berkolaborasi dengan orang lain; 3) Berpikir kritis dan dapat memecahkan masalah; 4) Kreativitas dan Inovasi (Trilling \& Fadel 2009, Binkley 2012, Scott 2015, Häkkinen, dkk. 2016).

Di Indonesia kemampuan abad 21 sudah diintegrasikan dalam kurikulum 2013 untuk dapat dilaksanakan dalam kegiatan pembelajaran. Pada Penyempurnaan pola pikir kurikulum 2013 dikembangkan dengan penyempurnaan pola pikir yang diantaranya 1) Penguatan pola pembelajaran yang berpusat pada siswa; 2) Penguatan pola pembelajaran interaktif (interaktif guru-siswamasyarakat-lingkungan alam, sumber/media lainnya); 3) Penguatan pola pembelajaran secara jejaring (siswa dapat menimba ilmu dari siapa saja dan dari mana saja yang dapat dihubungi serta diperoleh melalui internet); 4) Penguatan pembelajaran aktif-mencari (pembelajaran siswa aktif mencari semakin diperkuat dengan pendekatan pembelajaran saintifik); 5) Penguatan pola belajar sendiri dan kelompok (berkolaborasi); 6) Penguatan pembelajaran berbasis multimedia; 7) Penguatan pola pembelajaran berbasis klasikal-massal dengan tetap memperhatikan pengembangan potensi khusus yang dimiliki setiap siswa; 8) Penguatan pola pembelajaran ilmu pengetahuan jamak; dan 9) Penguatan pola pembelajaran kritis (Peraturan Mentri Pendidikan dan Kebudayaan 2014).

Dari beberapa kemampuan abad 21 yang disebutkan di atas, salah satu kemampuan yang penting untuk dimiliki dan dikembangkan siswa yaitu kemampuan berkolaborasi. Kemampuan berkolaborasi sangat penting untuk dikembangkan supaya siswa dapat bekerjasama dalam perbedaan kelompok sebagai bekal untuk menghadapi era globalisasi abad ke-21 (Muiz, dkk. 2016). Menurut KBBI kata kolaborasi adalah bekerja sama, pastinya bekerjasama dengan orang lain secara efektif sesuai dengan tanggung jawab dan kemampuan individu. Agar siswa dapat memiliki kemampuan berkolaborasi maka guru harus mampu melatihkannya dengan menggunakan strategi yang tepat dalam kegiatan pembelajaran, misalnya dengan melakukan kegiatan praktikum pada saat pelaksanaan pembelajaran. Siswa dapat dikatakan memiliki kemampuan berkolaborasi, maka harus memenuhi 3 komponen kemampuan berkolaborasi yaitu: a) Menunjukkan kemampuan bekerja secara efektif dan menghargai keberagaman tim; b) Menunjukan fleksibilitas dan kemauan untuk menerima pendapat orang lain dalam mencapai tujuan bersama. c) Mengemban tanggung jawab bersama dalam bekerja kolaboratif dan menghargai kontribusi setiap anggota tim (Trilling \& Fadel, 2009).

Siswa dapat dikatakan memiliki kemampuan berkolaborasi, tentunya harus ada instrumen penilaian yang tepat untuk digunakan dalam mengidentifikasi kemampuan berkolaborasi siswa. Penggunaan instrumen penilaian kemampuan berkolaborasi dapat mengidentifikasi sesuai tujuan peneliti misalnya profil, peningkatan dan korelasi dengan motivasi belajar. Peneliti di Indonesia sudah melakukan penilaian kemampuan berkolaborasi dengan instrumen diantaranya berupa angket, penilaian diri bahkan soal tes. Berdasarkan penelitian yang dilakukan oleh Daud dan Dewanto, kemampuan kolaborasi siswa mengalami peningkatan setelah penyampaian materi diketahui dari hasil angket dan observasi akhir lebih besar dari hasil angket dan observasi awal (Daud \& Dewanto 2016). Peneliti menganggap masih perlu adanya pengembangan rubrik standar untuk menilai kemampuan berkolaborasi. Maka dari itu peneliti bertujuan untuk mengembangakan instrumen berupa rubrik penilaian kemampuan berkolaborasi siswa. Instrumen yang dikembangkan pada penelitian ini mengacu pada Rubrik Standar dari International Reading Association (IRA). Pada rubrik standar, aspek yang mencakup kemampuan berkolaborasi yaitu kontribusi (Contributions), manajemen waktu (Time management), pemecahan masalah (Problem solving), bekerja dengan orang lain (Working with others), teknik penyelidikan (Research techniques) dan sintesis (Synthesis) (Read Write Think 2005), namun aspek sintesis tidak dikembangkan. Rubrik ini nantinya akan digunakan pada kegiatan pembelajaran dengan materi pemantulan cahaya.

Kegiatan pembelajaran yang akan digunakan yaitu harus berpusat pada siswa (student centered) yang sesuai dengan prinsip kurikulum 2013. Salah satu cara agar kegiatan pembelajaran dapat

e-Jurnal: http://doi.org/10.21009/1 
berpusat pada siswa yaitu dengan melakukan kegiatan praktikum secara berkelompok. Selain itu, kegiatan praktikum secara berkelompok juga dapat melatihkan siswa untuk berkolaborasi dalam melakukan investigasi permasalahan yang diberikan guru. Kelompok praktikum ini dapat disebut Grup Investigasi yang merupakan salah satu pembelajaran kooperatif dengan menempatkan siswa ke dalam kelompok-kelompok kecil, kemudian siswa merencanakan dan melaksanakan penyelidikannya dalam memecahkan masalah (Asriningsih, dkk. 2016). Penggunaan pembelajaran kooperatif ini juga dapat berpotensi memperkecil kesalahpahaman siswa terhadap konsep fisika (Samsudin, dkk. 2014). Model pembelajaran grup investigasi dapat meningkatkan hasil beajar siswa (Khaeriyah 2016) dan model pembelajaran grup investigasi juga mampu menumbuhkan sikap ilmiah siswa (Istikomah, dkk. 2010). Salah satu sikap ilmiah siswa yaitu kemampuan berkolaborasi.

Menurut Sharan (dalam (Asriningsih, dkk. 2016)) grup investigasi terdiri dari poin-poin sebagai berikut: 1) Mengidentifikasi topik, 2) Perencanaan penyelidikan, 3) Melaksanakan investigasi, 4) Menyiapkan dan menyajikan laporan akhir, dan 5) Evaluasi. Sehingga grup investigasi sangat cocok digunakan sebagai strategi dalam melaksanakan kegiatan pembelajaran untuk melatihkan kemampuan berkolaborasi.

\section{METODE PENELITIAN}

Metode penelitian yang digunakan dalam penelitian ini adalah metode penelitian dan pengembangan instruksional model 4D (define, design, develop, and disseminate) (Thiagarajan, dkk., 1974), namun dibatasi hanya sampai tahap 2D (define and design). Pada tahap definisi (define) dilakukan analisis terhadap rubrik standar kemampuan berkolaborasi yang dikembangkan oleh International Reading Association (IRA) (Read Write Think 2005). Pada tahap desain (design), dilakukan perancangan (desain) pengembangan rubrik kemampuan berkolaborasi.

\section{HASIL DAN PEMBAHASAN}

Setelah melakukan kajian terkait rubrik standar kemampuan berkolaborasi, kemudian menentukan desain pengembangan dari rubrik kemampuan berkolaborasi, berikut adalah pemaparan mengenai proses desain pengembangan rubrik kemampuan berkolaborasi.

\section{Tahap Definisi (Define)}

Kemampuan berkolaborasi siswa merupakan salah satu kemampuan yang penting untuk dimiliki oleh siswa pada abad 21 ini. Kemampuan berkolaborasi akan dapat diidentifikasi dengan menggunakan instrumen yang tepat dan sesuai dengan keadaan atau karakateristik siswa yang ada di Indonesia. Pada tahap ini peneliti menganalisis semua aspek yang terdapat pada rubrik standar kemampuan berkolaborasi. Rubrik standar kemampuan berkolaborasi dari International Reading Association (IRA) ini memiliki 5 aspek yaitu kontribusi (Contributions), manajemen waktu (Time management), pemecahan masalah (Problem solving), bekerja dengan orang lain (Working with others), teknik penyelidikan (Research techniques) dan sintesis (Synthesis) (Read Write Think 2005). Aspek kontribusi (Contributions) merupakan aspek yang menjelaskan bagaimana karakteristik sikap siswa dalam memberikan gagasan atau ide sehingga mampu berpasrtisipasi ketika kegiatan diskusi kelompok. Aspek manajemen waktu (Time management) merupakan aspek yang menjelaskan karakteristik sikap siswa dalam mengatur waktu untuk menyelesaikan tugas kelompok dengan tepat waktu. Aspek pemecahan masalah (Problem solving) merupakan aspek yang menjelaskan karakteristik siswa dalam melakukan usaha untuk menyelesaikan permasalahan. Aspek bekerja dengan orang lain (Working with others) merupakan aspek yang menjelaskan karakteristik sikap siswa dalam mendengarkan pendapat/ide rekan kelompok dan membantu menyelesaikan tugas kelompok. Aspek teknik penyelidikan (Research techniques) merupakan aspek yang menjelaskan karakteristik sikap siswa dalam mencari sumber-sumber konten atau teori untuk menjawab/memecahkan permasalahan. Selanjutnya aspek sintesis (Synthesis) merupakn aspek yang menjelaskan karakteristik sikap siswa dalam menyusun gagasan yang kompleks kedalam susunan yang struktur. Namun dalam penelitian ini, aspek sintesis tidak digunakan karena siswa SMP dianggap belum siap untuk mensintesis gagasan yang kompleks. 
Berdasarkan rubrik standar setiap aspek diberi ketetapan skor 1 sampai 4 dengan pernyataan yang berbeda-beda (Read Write Think 2005). Berikut adalah salah satu aspek yaitu kontribusi (Contributions) dibagi ke dalam empat pernyataan dengan skor 1 sampai 4 dari Rubrik Standar Kemampuan berkolaborasi (Read Write Think 2005).

Pernyataan ke-1 diberi skor 1 :

"In large-and small group discussions, rarely shares helpful ideas. Participates minimally or not at all."

Pernyataan ke-2 diberi skor 2:

"In large-and small group discussions, sometimes shares helpful ideas. Makes the required effort to participate but no more."

Pernyataan ke-3 diberi skor 3:

"In large- and smallgroup discussions, often shares helpful ideas. Clearly strives to participate."

Pernyataan ke-4 diberi skor 4:

"In large- and smallgroup discussions, shares helpful ideas. Leads the discussion and makes a strong effort to contribute."

Pernyataan-pernyataan dari aspek kontribusi tersebut kemudian diadaptasi dan dimodifikasi ke dalam bahasa Indonesia, dengan redaksi seperti berikut.

Pernyataan ke-1 diberi skor 1:

"Dalam diskusi kelompok besar atau kecil tidak memberi gagasan dan tidak ikut berpartisipasi."

Pernyataan ke-2 diberi skor 2:

"Dalam diskusi kelompok besar atau kecil jarang (hanya 1 kali) memberi gagasan. Namun sedikit (hanya 1 kali) berpartisipasi."

Pernyataan ke-3 diberi skor 3:

"Dalam diskusi kelompok besar atau kecil sering (hanya 2 kali) memberi gagasan. Namun tidak sering (hanya 2 kali) berkontribusi dalam berpartisipasi."

Pernyataan ke-4 diberi skor 4:

"Dalam diskusi kelompok besar atau kecil sangat sering (lebih dari 2 kali) memberi gagasan yang menjadi acuan dalam diskusi. Mampu memimpin diskusi dan sering (lebih dari 2 kali) berkontribusi dalam berpartisipasi."

Pernyataan-pernyataan dari rubrik standar diadaptasi dan dimodifikasi berdasarkan pertimbangan keadaan karakteristik siswa dan bahasa Indonesia. Pada aspek kontribusi, siswa akan mendapatkan skor 1 jika siswa menunjukan karakteristik sikapnya saat kerja kelompok sesuai dengan pernyataan ke-1. Siswa akan mendapatkan skor 2 ketika menunjukan karakteristik sikapnya saat kerja kelompok sesuai dengan pernyataan ke-2. Siswa akan mendapatkan skor 3 ketika menunjukan karakteristik sikapnya saat kerja kelompok sesuai dengan pernyataan ke-3. Siswa akan mendapatkan skor 4 ketika menunjukan karakteristik sikapnya saat kerja kelompok sesuai dengan pernyataan ke-4.

Rubrik ini sangat bermanfaat dalam mengukur kemampuan berkolaborasi siswa, walaupun masih membutuhkan perencanaan dan strategi yang tepat dalam pelaksanaannya.

\section{Tahap Desain (design)}

Pada tahap ini, peneliti menjelaskan bagaimana rancangan atau desain rubrik kemampuan berkolaborasi. Rubrik kemampuan berkolaborasi didesain dengan mempertimbangkan keadaan karakteristik siswa dan bahasa yang mudah dipahami, sehingga dapat digunakan oleh semua orang 
(observer) dalam kegiatan pembelajaran pada semua materi. Berikut adalah desain modifikasi rubrik kemampuan berkolaborasi.

TABEL 1. Desain rubrik kemampuan berkolaborasi.

\begin{tabular}{|c|c|c|c|c|c|}
\hline Aspek & 1 & 2 & 3 & 4 & Skor \\
\hline Kontribusi & $\begin{array}{l}\text { Dalam diskusi } \\
\text { kelompok besar atau } \\
\text { kecil tidak memberi } \\
\text { gagasan dan tidak } \\
\text { ikut berpartisipasi. }\end{array}$ & $\begin{array}{l}\text { Dalam diskusi } \\
\text { kelompok besar atau } \\
\text { kecil jarang (hanya } 1 \\
\text { kali) memberi } \\
\text { gagasan. Namun } \\
\text { sedikit (hanya } 1 \text { kali) } \\
\text { berpartisipasi. }\end{array}$ & $\begin{array}{l}\text { Dalam diskusi } \\
\text { kelompok besar atau } \\
\text { kecil sering (hanya } 2 \\
\text { kali) memberi } \\
\text { gagasan. Namun tidak } \\
\text { sering (hanya } 2 \text { kali) } \\
\text { berkontribusi dalam } \\
\text { berpartisipasi. }\end{array}$ & $\begin{array}{l}\text { Dalam diskusi } \\
\text { kelompok besar atau } \\
\text { kecil sangat sering } \\
\text { (lebih dari } 2 \text { kali) } \\
\text { memberi gagasan } \\
\text { yang menjadi acuan } \\
\text { dalam diskusi. } \\
\text { Mampu memimpin } \\
\text { diskusi dan sering } \\
\text { (lebih dari } 2 \text { kali) } \\
\text { berkontribusi dalam } \\
\text { berpartisipasi. }\end{array}$ & $1-4$ \\
\hline
\end{tabular}

\begin{tabular}{|c|c|c|c|c|c|}
\hline $\begin{array}{l}\text { Manajemen } \\
\text { waktu }\end{array}$ & $\begin{array}{l}\text { Tidak mengerjakan } \\
\text { tugas, sehingga } \\
\text { menyebabkan } \\
\text { kelompok } \\
\text { memperpanjang batas } \\
\text { waktu pengerjaannya. }\end{array}$ & $\begin{array}{l}\text { Tugas diselesaikan, } \\
\text { namun terlambat }>3 \\
\text { menit dari waktu } \\
\text { yang ditentukan. } \\
\text { Sehingga } \\
\text { menyebabkan } \\
\text { kelompok } \\
\text { memperpanjang batas } \\
\text { waktu pengerjaannya. }\end{array}$ & $\begin{array}{l}\text { Tugas diselesaikan, } \\
\text { namun terlambat } \leq 3 \\
\text { menit dari waktu } \\
\text { yang ditentukan. } \\
\text { sehingga masih tidak } \\
\text { menyebabkan } \\
\text { kelompok } \\
\text { memperpanjang batas } \\
\text { waktu pengerjaannya. }\end{array}$ & $\begin{array}{l}\text { Menyelesaikan tugas } \\
\text { tepat waktu atau } \\
\text { selesai sebelum batas } \\
\text { waktu, sehingga tidak } \\
\text { pernah menyebabkan } \\
\text { kelompok } \\
\text { memperpanjang batas } \\
\text { waktu pengerjaannya. }\end{array}$ & $1-4$ \\
\hline $\begin{array}{l}\text { Pemecahan } \\
\text { masalah }\end{array}$ & $\begin{array}{l}\text { Tidak ada usaha } \\
\text { untuk menemukan } \\
\text { dan memberi jawaban } \\
\text { atas permasalahan } \\
\text { serta memberikan } \\
\text { semua tugas } \\
\text { (mengandalkan) } \\
\text { kepada orang lain. }\end{array}$ & $\begin{array}{l}\text { Jarang (hanya } 1 \text { kali) } \\
\text { melakukan usaha } \\
\text { untuk mencari } \\
\text { jawaban atas } \\
\text { permasalahan dan } \\
\text { menggunakan solusi } \\
\text { yang digagaskan oleh } \\
\text { orang lain. }\end{array}$ & $\begin{array}{l}\text { Sering (hanya } 2 \text { kali) } \\
\text { melakukan usaha } \\
\text { untuk mencari } \\
\text { jawaban atas } \\
\text { permasalahan, tetapi } \\
\text { solusi yang } \\
\text { ditemukan hasil } \\
\text { pengembangan dari } \\
\text { gagasan orang lain. }\end{array}$ & $\begin{array}{l}\text { Sangat sering (lebih } \\
\text { dari } 2 \text { kali) } \\
\text { melakukan usaha } \\
\text { yang jelas untuk } \\
\text { menemukan dan } \\
\text { memberikan gagasan } \\
\text { sendiri untuk } \\
\text { menjawab } \\
\text { permasalahan. }\end{array}$ & $1-4$ \\
\hline $\begin{array}{l}\text { Bekerja } \\
\text { dengan } \\
\text { orang lain }\end{array}$ & $\begin{array}{l}\text { Tidak mendengarkan } \\
\text { pendapat orang lain } \\
\text { atau tidak membantu } \\
\text { orang lain dan tidak } \\
\text { berpartisipasi dalam } \\
\text { kerja kelompok. }\end{array}$ & $\begin{array}{l}\text { Jarang (hanya } 1 \text { kali) } \\
\text { mendengarkan } \\
\text { pendapat orang lain } \\
\text { dan jarang (hanya } 1 \\
\text { kali) membantu orang } \\
\text { lain dikarenakan } \\
\text { kesulitan untuk kerja } \\
\text { kelompok. }\end{array}$ & $\begin{array}{l}\text { Sering (hanya } 2 \text { kali) } \\
\text { mendengarkan } \\
\text { pendapat orang lain } \\
\text { dengan baik dan } \\
\text { sering (hanya } 2 \text { kali) } \\
\text { membantu orang lain, } \\
\text { namun tidak } \\
\text { memudahkan dalam } \\
\text { kerja kelompok. }\end{array}$ & $\begin{array}{l}\text { Sangat sering (lebih } \\
\text { dari } 2 \text { kali) } \\
\text { mendengarkan } \\
\text { pendapat orang lain } \\
\text { dengan baik dan } \\
\text { sangat sering (lebih } \\
\text { dari } 2 \text { kali) membantu } \\
\text { orang lain sehingga } \\
\text { memudahkan dalam } \\
\text { kerja kelompok. }\end{array}$ & $1-4$ \\
\hline $\begin{array}{l}\text { Teknik } \\
\text { Peyelidikan }\end{array}$ & $\begin{array}{l}\text { Tidak mencari } \\
\text { berbagai sumber } \\
\text { (hanya terfokus pada } \\
\text { satu sumber) dan } \\
\text { tidak mencatat } \\
\text { informasi. }\end{array}$ & $\begin{array}{l}\text { Jarang mecari } \\
\text { berbagai sumber } \\
\text { (hanya terfokus pada } \\
2 \text { sumber) dan } \\
\text { mencatat informasi, } \\
\text { tetapi tidak detail. }\end{array}$ & $\begin{array}{l}\text { Sering mencari } \\
\text { berbagai sumber } \\
\text { (hanya terfokus pada } \\
3 \text { sumber) dan selalu } \\
\text { mencatat informasi, } \\
\text { tetapi tidak detail. }\end{array}$ & $\begin{array}{l}\text { Sangat sering mencari } \\
\text { berbagai sumber } \\
\text { (terfokus pada lebih } \\
\text { dari } 3 \text { sumber) dan } \\
\text { selalu mencatat } \\
\text { informasi secara } \\
\text { detail. }\end{array}$ & $1-4$ \\
\hline
\end{tabular}

Dari TABEL 1, menunjukan bahwa desain rubrik kemampuan berkolaborasi sudah lengkap yang berdasarkan hasil adaptasi dan modifikasi rubrik standar (Read Write Think 2005). Rubrik ini akan 
digunakan oleh peneliti dalam kegiatan pembelajaran pada materi pemantulan cahaya. Kegiatan pembelajaran yang akan dilakukan yaitu pembelajaran yang berpusat pada siswa (student centered) yang sesuai dengan prinsip kurikulum 2013. Salah satu strategi agar terjadinya pembelajaran berpusat pada siswa dan pembelajaran inovatif yang dapat diterapkan di kelas adalah model pembelajaran kooperatif. Model pembelajaran kooperatif dibagi menjadi beberapa tipe. Salah satunya ialah tipe Group Investigation (GI) (Razak, dkk. 2016). Model grup investigasi ini akan digunakan dalam kegiatan praktikum pada materi pemantulan cahaya. Siswa akan dibagi ke dalam beberapa kelompok, tiap kelompok beranggotakan 4 sampai 6 orang. Kegiatan praktikum pemantulan cahaya mengguanakan KIT alat optik dan setiap kelompok diberikan Lembar Kegiatan Siswa (LKS), di dalamnya terdapat permasalahan yang harus dipecahkah secara berkelompok. Ketika kegiatan pembelajaran berlangsung, seorang guru atau observer menilai kemamapuan berkolaborasi siswa dengan menggunakan rubrik yang dikembangkan ini. Agar lebih teliti pada saat menilai siswa, peneliti akan menyimpan satu orang observer (orang yang menilai) di setiap kelompok. Berikut adalah denah posisi siswa dalam kelompok dan posisi seorang observer.

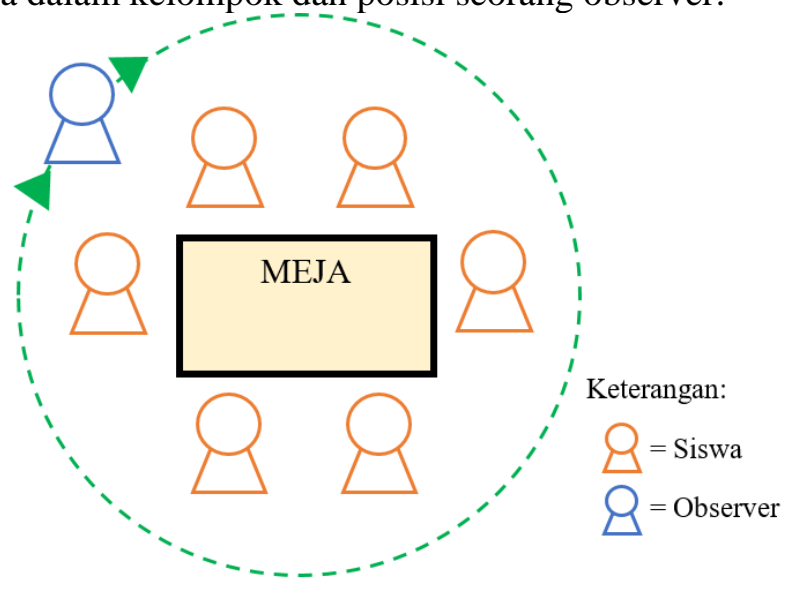

GAMBAR 1. Denah posisi siswa dalam kelompok dan observer.

Dari GAMBAR 1, menjelaskan denah posisi siswa ketika di dalam kelompok yang beranggotakan 6 orang dan seorang observer yang menilai kemampuan berkolaborasi siswa berada di samping siswa. Garis lingkaran hijau yang putus-putus menggambarkan seorang observer harus berkeliling dalam menilai siswa agar diperoleh hasil yang lebih teliti. Penskoran untuk masing-masing aspek kemampuan berkolaborasi siswa masih sama dengan "collaborative work skills rubric" (Read Write Think 2005) yaitu skor 1 sampai 4.

\section{SIMPULAN}

Salah satu kemampuan abad 21 yang penting untuk dimiliki oleh setiap siswa yaitu kemampuan berkolaborasi. Aspek-aspek yang mencakup kemampuan berkolaborasi terdapat pada rubrik standar yaitu kontribusi (Contributions), manajemen waktu (Time management), pemecahan masalah (Problem solving), bekerja dengan orang lain (Working with others), teknik penyelidikan (Research techniques) dan sintesis (Synthesis) (Read Write Think 2005) dengan penskoran dari hasil modifikasi dan melihat situasi keadaan di Indonesia. Penelitian ini terbatas sampai tahap desain instrumen rubrik kemampuan berkolaborasi untuk siswa SMP pada materi pemantulan cahaya.

Penelitian selanjutnya diharapkan sampai pada tahapan develop, yaitu tahap judgment oleh para ahli, perbaikan instrumen tes dari hasil judgement, kemudian pengujian pada beberapa sampel. Setelah itu memasuki tahap disseminate. Peneliti mengharapkan pengembangan instrumen rubrik kemampuan berkolaborasi ini dapat digunakan pada semua materi Fisika/ IPA lainnya sehingga menjadi rubrik standar di Indonesia. 


\section{UCAPAN TERIMAKASIH}

Ucapan terima kasih diberikan kepada rekan-rekan dan bapak/ibu tim dosen payung penelitian Multimedia Based Integrated Instruction $\left(\mathrm{MBI}_{2}\right)$ yang telah membimbing penulis dalam melakukan penelitian.

\section{REFERENSI}

Asriningsih, I., Saepuzaman, D. \& Ferranie, S., 2016. Penerapan Strategi Metakognisi pada Pembelajaran Kalor untuk Mengidentifikasi Proses Berpikir Siswa dalam Menyelesaikan Masalah. Seminar Nasional Fisika, Volume V, pp. 1-6.

Binkley, M., 2012. Defining twenty-first century skills. Assesment and Teaching of 21st Century Skills. Dordrecht: Springer.

Daud, A. P. M. \& Dewanto, 2016. Implementasi Pendekatan Ilmiah (Scientific Approach) dalam Meningkatkan Kemampuan Kolaborasi dan Hasil Belajar Ssiswa di SMK Negeri 5 Surabaya. Implementasi Pendekatan Ilmiah (Science Approach), pp. 123-129.

Häkkinen, P., Järvelä, S., Mäkitalo-Siegl, K., Ahonen, A., Näykki, P., \& Valtonen, T. (2016). Preparing Teacher-students for Twenty-firstcentury Learning Practices (PREP 21): A Framework for Enhancing Collaborative Problem-solving and Strategic Learning Skills. Teachers and Teaching theory and practice, pp. 1-17.

Istikomah, H., Hendratto, S. \& Bambang, S., 2010. Penggunaan Model Pembelajaran Group Investigation untuk Menumbuhkan Sikap Ilmiah Siswa. Jurnal Pendidikan Fisika Indonesia, pp. $40-43$.

Khaeriyah, F., 2016. Peningkatan Hasil Belajar Ilmu Pengetahuan Sosial Melalui Metode Cooperative Learning Teknik Grup Investigasi. Jurnal Pendidikan Dasar, pp. 209-224.

Muiz, A., Wilujeng, I., Jumadi, \& Senam. (2016). Implementasi Model Susan Loucks-Horsley Terhadap Communication and Collaboration Peserta Didik SMP. Unnes Science Education Journal , pp. 1079-1084.

Peraturan Menteri Pendidikan dan Kebudayaan Nomor 58 Tahun 2014, Tentang kurikulum 2013 Sekolah Menegah/Madrasah Tsanawiyah, Permendikbud, Jakarta.

Razak, A., Kusmayadi, T. A. \& R., 2016. Eksperimentasi Model Pembelajaran Kooperatif Tipe Group Investigation (GI) dan Think Pair Share (TPS) dengan Pendekatan Saintifik pada Materi Relasi dan Fungsi Ditinjau dari Kemampuan Penalaran Siswa SMP Negeri Kelas VIII di Kabupaten Karanganyar Tahun Ajaran 2014/2015. Jurnal Elektronik Pembelajaran Matematika, Volume 4, pp. 215-228.

Read Write Read Write Think 2005, Collaborative Work Skills Rubric, International Reading Association/Ncte.

Samsudin, A., Liliawati, W., Sustrisno, A. D., Suhendi, E., \& Kaniawati, I., 2014. The Use of Computer Simulation in Cooperative Learning to Minimize Students' Misconceptions of Momentum and Impulse. ICAET, pp. 72-74.

Scott, C. L., 2015. The Futures of Learning 2: What Kind of Learning for The 21st Century?. Education Research and Foresight $\bullet$ Working Papers, pp. 1-14.

Thiagarajan, S., Semmel, D. S. \& Semmel, M. I., 1974. Instructional Development for Training Teachers of Exceptional Children, Minneapolis, Minnesota. Leadership Training Institute/Special Education, University of Minnesota.

Trilling, B. \& Fadel, C., 2009. 21st Century Skills: Learning for Life in Our Times. Amerika: JosseyBass Wiley. 
